http://jmscr.igmpublication.org/home/ ISSN (e)-2347-176x ISSN (p) 2455-0450

crossref DOI: https://dx.doi.org/10.18535/jmscr/v8i1.108

Journal Of Medical Science And Clinical Research

\title{
Aetiopathaological Study of Hoarseness of Voice
}

\author{
Authors \\ Dr Shushma Konda ${ }^{1}$, Dr S.Surya Prakasa Rao ${ }^{2 *}$, Dr T.V.S.S.N. Leela Prasad, \\ Dr K.V.Madhavi Latha ${ }^{4}$ \\ ${ }^{1}$ Junior Resident of ENT, Andhra Medical College, Visakhapatnam, India \\ ${ }^{2}$ Professor of ENT, Andhra Medical College, Visakhapatnam, India \\ ${ }^{3}$ Assistant Professor of ENT, Andhra Medical College, Visakhapatnam, India \\ ${ }^{4}$ Senior Consultant, Gynaecologist, Visakhapatnam, India \\ *Corresponding Author \\ Dr S.Surya Prakasa Rao \\ Professor of ENT, Andhra Medical College, Visakhapatnam, India
}

\begin{abstract}
Background: Hoarseness is one of the most frequently found symptoms in otolaryngology. It is invariably the earliest manifestation of various conditions affecting directly or indirectly the larynx ranging from benign to malignant lesions. Hoarseness indicates an abnormality at the level of glottis resulting from structural or physiologic disorders. A careful and complete examination is mandatory because of impending brisk airway obstruction.

Aim: The aim is to evaluate various etiological factors and different pathologiesin clinical presentation of hoarseness of voice.

Materials and Methods: This is an observational study consisting of 50 cases of hoarseness carried out in the department of ENT, Govt. ENT Hospital, Visakhapatnam, during August 2018 and July 2019. A detailed history was taken, and all patients were subjected to the IDL examination. Findings were confirmed by videolaryngoscopy, direct laryngoscopy, and micro laryngoscopy.

Results: The majority of patients were seen in the age group of 41-60 years (40\%). Male predominance was observed with a Male:Female ratio of 2.3:1.Most commonly seen in Manual labourers (hawkers) (35\%). Maximum patients presented with a duration of 1-3 months. Smoking was the commonest habit in $40 \%$ of cases. The commonest cause was laryngeal malignancy (30\%)followed by polyp (20\%), vocal cord palsy (14\%).The least common cause was vocal cord cyst seen in $2 \%$ cases.

Conclusion: Hoarseness of voice was most commonly seen in middle-aged males. Most of the patients attended with complaint of hoarseness with duration of 1-3 months. It was mostly seen in manual labourers (hawkers) along with habits of smoking and alcohol consumption, chewing tobacco preparations, and vocal abuse. Suspicion of Malignancy and its exclusion should be considered in all the cases with hoarseness.

Keywords: hoarseness of voice, laryngeal malignancy, smoking, vocal cord polyp.
\end{abstract}

\section{Introduction}

The normal voice should possess certain characteristics of pitch, loudness, and quality, which make clear meaning and elicits an emotional response to ensure a pleasant tonal effect upon the listener. Hoarseness can be defined 
as a quality of voice that is rough, grating, harsh, and lower in pitch than normal. Hoarseness is obviously a symptom and not a disease ${ }^{1}$. It is often caused by benign or self-limited conditions and may also be the presenting symptom of a more severe or progressive condition. For the production of hoarseness of voice, there will be a change in anatomical structures and physiopathological processes.

In the words of Chevalier Jackson, "Hoarseness is a symptom of utmost significance and calls for a separate consideration as a subject because of the frequency of its occurrence as a distinct signal of malignancy and other conditions. "Hoarseness has a lifetime prevalence of 29.9 percent and a point prevalence of 6.6 percent in adults aged 65 years or under.

Hoarseness is more prevalent in certain groups, such as teachers and older adults, but all age groups and both genders can beaffected ${ }^{2}$.

\section{Aim}

To evaluate various etiological factors and different pathologies in clinical presentation of hoarseness of voice.

\section{Materials and Methods}

This is an observational study comprising of 50 cases of hoarseness of voice which was carried out in the department of ENT, Govt. ENT Hospital, Visakhapatnam, during August 2018 and July 2019.

Inclusion Criteria Patients presenting with hoarseness of voice of $\geq 2$ weeks duration were included in the present study.

\section{Exclusion Criteria}

1. Age group below 5 years.

2. Voice disorders other than hoarseness like rhinolalia aperta, rhinolaliaclausa, articulation disorders, functional disorders, and central nervous systems like bulbar palsy, Wegner's granulomatosis, multiple sclerosis, stroke, and Parkinson's disease.

Written informed consent was taken from all the individuals in the study. A thorough evaluation of 50 patients was done by taking a detailed history regarding the symptoms. Then the patients were subjected to general physical, systemic \& nose, ear \& throat examinations. The clinical diagnosis of laryngeal lesions was made on the basis of clinical presentation, IDL examination. Any patient with suspected lesions in the larynx were examined by videolaryngoscopy with $70^{\circ}$ endoscope, direct laryngoscopy, or flexible nasopharyngolaryngoscopy. Later under general anesthesia, biopsy was taken and sent for histopathological examination to confirm the diagnosis.

\section{Results}

Table 1: Age and sex distribution

\begin{tabular}{|l|c|c|c|}
\hline Age group & Male & Female & No. of cases \\
\hline $0-15$ & 1 & 1 & $2(4 \%)$ \\
\hline $16-30$ & 5 & 1 & $6(12 \%)$ \\
\hline $31-40$ & 5 & 7 & $12(24 \%)$ \\
\hline $41-60$ & 16 & 4 & $20(40 \%)$ \\
\hline$>61$ & 8 & 2 & $10(20 \%)$ \\
\hline Total & 35 & 15 & 50 \\
\hline
\end{tabular}

Table 2: Etiological factors

\begin{tabular}{|l|c|c|c|}
\hline Predisposing factors & Male & Female & Total \\
\hline Smoking & 18 & 2 & $20(40 \%)$ \\
\hline Vocal abuse & 7 & 11 & $18(36 \%)$ \\
\hline Alcohol & 15 & & $15(30 \%)$ \\
\hline Chewing of tobacco preparations & 8 & 2 & $10(20 \%)$ \\
\hline No factor & 7 & 3 & $10(20 \%)$ \\
\hline
\end{tabular}


Table 3 -Complaints with duration:

\begin{tabular}{|c|c|c|c|c|c|c|c|}
\hline \multirow[t]{2}{*}{ Complaints } & \multicolumn{5}{|c|}{ Duration (months) } & \multirow[t]{2}{*}{ Total } & \multirow[t]{2}{*}{$\%$} \\
\hline & $<1$ & $1-3$ & $3-6$ & 6-12 & $>12$ & & \\
\hline Hoarseness & 7 & 18 & 9 & 8 & 7 & 50 & 100 \\
\hline Dysphagia & 10 & 5 & & & & 15 & 30 \\
\hline Breathlessness & 9 & 3 & & & & 12 & 24 \\
\hline Cough & 10 & & & & & 10 & 20 \\
\hline Stridor & 8 & & & & & 8 & 16 \\
\hline Foreignbody sensation & 3 & 2 & & & & 5 & 10 \\
\hline Neck swelling & & & 3 & 2 & & 4 & 8 \\
\hline
\end{tabular}

\section{Pathology}

\begin{tabular}{|l|c|c|c|}
\hline ETIOLOGY & MALES & FEMALES & TOTAL \\
\hline Laryngeal malignancy & 12 & 2 & $15(30 \%)$ \\
\hline Vocalcord polyp & 4 & 6 & $10(20 \%)$ \\
\hline Vocal cord palsy & 5 & 2 & $7(14 \%)$ \\
\hline Chronic laryngitis & 4 & 2 & $6(12 \%)$ \\
\hline Vocal nodule & 2 & 3 & $5(10 \%)$ \\
\hline papilloma & 3 & 1 & $4(8 \%)$ \\
\hline hemangioma & 2 & & $2(4 \%)$ \\
\hline Vocal cord cyst & 1 & & $1(2 \%)$ \\
\hline
\end{tabular}

\section{Discussion}

Among 50cases, 35(70\%) were males, and $15(30 \%)$ were females. Male predominance was observed with male to female ratio of 2.3:1. Parikh et al. $^{3}$ and Karan Sharma et al. ${ }^{4}$ also reported a male: female ratio of 2:1.Majority of the patients presented in the age range of 4160years (40\%) followed by 31-40 years $(24 \%)$, $>61$ years age (20\%), 16-30years (12\%), 0-15 years $(4 \%)$. Baitha et al. ${ }^{5}$ found the majority of patients $(28.18 \%)$ in the age group of $31-40$ years. Male predominance was seen $(45.7 \%)$ in the 41-60 years age group, while female dominance was seen $(46.6 \%)$ in the 31-40years age group. The largest group were labourer (hawkers) (36\%) followed by private jobs (26\%), housewives $(22 \%)$, students $(16 \%)$. The same observation was made by Baitha et al. ${ }^{5}$, i.e., the majority of patients were of labourer class $(36.36 \%)$. The majority of the male patients were labourer $(36 \%)$, and females were housewives $(22 \%)$. Ghosh et al. ${ }^{6}$ found the majority of patients (29\%) were housewives. In our study, the most common etiological factor was smoking (40\%) followed by vocal abuse (36\%), alcohol (30\%), chewing of tobacco preparations, and no habits (20\%). Among males, Smoking was the most common etiological factor, while in females, voice abuse was most common. In a study by Pal KS et al. ${ }^{7}$ Smoking was noted in $33 \%$ of cases. Ghosh et al. ${ }^{6}$ showed vocal abuse in $72 \%$ of cases.

All cases presented with hoarseness of voice $(100 \%)$. Studies were done by Parik et al. ${ }^{3}$, and Mehta et al. ${ }^{8}$ noted that $100 \%$ of cases presented with hoarseness. Next common complaint was dysphagia in 15 cases $(30 \%)$, breathlessness in 12 cases $(24 \%)$, cough in 10 cases $(20 \%)$, stridor in 8 cases $(16 \%)$, foreign body sensation in 5 cases (10\%) and neck swelling in 4 cases $(8 \%)$. In study by Kamana sindhu et al. ${ }^{9}$ hoarseness of voice is the most common symptom seen in $92 \%$ of cases, and the other symptoms were foreign body sensation (25\%), breathiness $(23 \%)$, vocal fatigue $(10 \%)$, neck swelling (10\%), dysphagia $(8 \%)$, stridor (6\%), aphonia is the least commonly seen in $2 \%$ cases. Verma et al. $^{10}$ reported hoarseness in $73.92 \%$, difficulty in swallowing in $59.95 \%$, and cough with expectoration in $39.04 \%$. The duration of hoarseness ranged from 2 weeks to 4yrs. Most of them (36\%) presented with hoarseness of voice with 1-3 months duration. Other complaints were most common in the duration of $<1$ months. Hansa et al. ${ }^{11}$ found most of the presenting complaints $(61.35 \%)$ were seen 
with three months duration, $25.1 \%$ with 3-6 months and $10.76 \%$ with6-12 months duration. Batra et al. ${ }^{12}$ found $59 \%$ of patients within the first five months of the appearance of symptoms.

In our study, the most common pathology of hoarseness was laryngeal malignancies, which comprises of $30 \%$ (15cases) of hoarseness of voice. Glottic malignancy constitutes $53.3 \%$ of cases, while supraglottic malignancy constitutes $46.6 \%$ of cases. Among patients with malignancy, out of 15 cases, 12 males $(80 \%)$ and 3 females $(20 \%)$. It was comparable to the study by Baitha et al. $^{5}$ where the incidence of malignancy was $14.54 \%$. Ghosh et al. $^{6}$ and Parikh et al. ${ }^{3}$ study showed the incidence of malignancy of $8 \%$ and $12 \%$ and vocal nodule (4\%).

In our study, vocal cord polyp was seen in 10 Cases (20\%), which was more common in females $(60 \%)$ and males $(40 \%)$. Vocal abuse was noticed in all cases of vocal cord polyp. Mehta et al. ${ }^{8}$ found $11.66 \%$ cases, Parikh et al. ${ }^{3}$ found $15 \%$ cases, and Hansa et al. ${ }^{11}$ found $3.59 \%$ of cases of vocal cord polyp in their study.

Vocal cord palsy was seen in 7cases (14\%), of which 4 were unilateral (2left, 2right), and 3 were bilateral. The cause for vocal cord palsy includes idiopathic in 5 cases, and 2 cases were due to post thyroidectomy. In a study by Parikh et al., ${ }^{3}$ Batra et al. ${ }^{12}$ and Baitha et al. ${ }^{5}$, it was only 3\%, 9\%, and $9 \%$, respectively, with male to female ratioin Baitha et al. ${ }^{5}$ studywas 9:1.

Chronic laryngitis was seen in 6 cases $(12 \%)$, of which $4(66.6 \%)$ were males and $2(33.3 \%)$ were females. Smoking and GERD was the predisposing factor in these cases. Hansa et al. ${ }^{11}$, in his study, found $9.56 \%$ of chronic laryngitis. In a study by Kumar $\mathrm{H}$ et al. ${ }^{13}, 52 \%$ of the cases were affected with chronic laryngitis.

Squamous papilloma (8\%) was seen in 4cases, of which $3(75 \%)$ were males and $1(25 \%)$ female. Thisis correlated with Chavan SS et al., ${ }^{14} 11.6 \%$, KavithaY et al. ${ }^{15} 98 \%$, and $10 \%$ by Chaitanya V et al. $^{16}$

In our study, vocal nodules were seen in 5 cases. Among them, 3 were female patients, 2 were males. In studies by Soldatskil LuL et al. ${ }^{17}$, Schneider stickler B et al. ${ }^{18}$ and Martin RH et al. ${ }^{19}$ vocal nodule was the most common cause for hoarseness in children prevalence being $53.1 \%$, $60 \%$, and $57.5 \%$, respectively. Vocal cord cyst (2\%) was seen in 1 case.

\section{Conclusion}

In our study, the incidence of hoarseness of voice showed a male to female ratio of 2.3:1. Manual Labourers (hawkers) was the largest group (36\%) of patients with hoarseness of voice. Smoking (40\%) was the commonest etiological factor. The most common pathology of hoarseness was laryngeal malignancies, which comprises $30 \%$ of hoarseness of voice, followed by vocal cord polyp (20\%). Our conclusion was in middle-aged male patients presenting with hoarseness of voice of more than 1month duration along with habits of smoking, alcohol consumption and chewing tobacco preparations, the malignancy should be ruled out.

\section{References:}

1. Chevalier Jackson, Chevalier L. Jackson. Disease of ear, nose and throat $2^{\text {nd }}$ edition. W.B. Sounders compnay. 1959; 576.

2. Schwartz et al. Clinical practice guideline: Hoarseness (Dysphonia) OtolaryngologyHead and Neck Surgery (2009) 141, S1S31.

3. Baitha S, Raizada RM, Kennedy Singh AK, Puttewar MP, Chaturvedi VN (2002) Clinical profile of hoarsens of voice. Indian J Otolaryngol Head Neck Surg 54(1):14-18.

4. Parikh N (1991) Aetiology study of 100 cases of hoarseness ofvoice. Indian $\mathbf{J}$ Otolaryngol Head Neck Surg 43(2):71-73.

5. Karan Sharma et al. Direct laryngoscopic observations in progressive hoarseness of voice. Indian journal of otorhinolaryngology and head and neck surgery, Oct-Dec 2006; vol58,No:4:364367. 
6. Ghosh SK, Chattopadhyay S, Bora H, Mukherjee PB (2001)Micro laryngoscopic study of 100 cases of hoarsens of voice.Indian $\mathrm{J}$ Otolaryngol Head Neck Surg 53(4):270-272.

7. Pal KS, Kaushal AK, Nagpure PS, Agarwal G. Etiopathological study of 100 patients of hoarseness of voice: in a rural based hospital. Indian J Otolaryngol Head Neck Surg. 2014 Jan; 66(1):40-5.

8. Mehta AS (1985): An etiological study of hoarseness of voice. A thesis submitted formaster of surgery; Gujarat university.

9. Kamana Sindhu Paul, Amit Kaushal, P.S. Nagpure, and Gaurav Agarwal: Indian journal of otolaryngology Head and Neck surgery. 2014 Jan; 60 (1). 40-45.

10. Verma M S, Panda NK, Mann S.B.S, Mehra YW. Presentation of carcinoma larynx and laryngopharynx: An analysis of 840 cases. J Otology and Laryngology. 1990; 42(2):50-3.

11. Banjara H, Mungutwar V, Singh D, Gupta A. Hoarseness of Voice: A Retrospective Study of 251cases. International journal of Phonosurgery and Laryngology.2011; 1(1):21-27.

12. Batra K, Motwani G, Sagar PC (2004) Functional voice disorders and their occurrence in 100 patients of hoarseness as seen on fibreoptic laryngoscopy. Indian $\mathbf{J}$ Otolaryngol Head Neck Surg 56(2):91-95.

13. Kumar H, S Seth S. Clinicopathological Profile of Hoarseness of The Voice. The Internet Journal of Otorhinolaryngology. $2010 ; 13(1): 4102$.

14. Chavan SS, Yewale AG. Clinicopathological profile of patients with benign laryngeal lesions. Med Pulse International Journal of ENT. September2017;3(3):26-28.

15. Kavitha Y, Chaitanya V, Basavaraju KP. Tumors and tumor like lesions of larynx:a clinicopathological study. Int J
Otolarhinolaryngol Head Neck Surg 2018;4:794-9.

16. Chaitnaya V, Nikethan B. Clinicopathological study of nonneoplastic and neoplastic lesions of the larynx.Int $\mathbf{J}$ Intg Med Sci 2015;2(12):200-205.

17. Varalakshmi KP, Naik VS, Swapna RS, Sravani P, Padmaja MN. Laryngeal Biopsies with special references to malignant tumors: A Histological Study.Int J sci stud 2016;4(3):197-202.

18. Soldatskil LuL, Sorokina VT, Onufrieva EK, Fedorova OIu, Pogosova IE, Volod'kina VV. Hoarseness patterns in children. Vestn Otorinolaringol. $2010 ;$ 2):28-31.

19. Schneider-Stickler B. Voice disorders in childhood.HNO. 2012 Jul;60(7):590-4.

20. Martins RH, Hidalgo Ribeiro CB, Fernandes de Mello BM, Branco A, Tavares EL. Dysphonia in children. J Voice. 2012 Sep; 26(5):674. 